\title{
PATHWAY TO REOPENING ECONOMIC ACTIVITIES IN THE ECOWAS REGION AMIDST COVID-19 PANDEMIC
}

\author{
Frank 0. Ozoh *1凶 \\ ${ }^{* 1} \mathrm{Ph}$. D, Professor of Economics at the Department of Economics and Development Studies, \\ Alex Ekwueme Federal University, Ndufu-Alike, Ikwo, Ebonyi State, Nigeria
}

DOI: https://doi.org/10.29121/granthaalayah.v8.i6.2020.363

Article Type: Research Article

Article Citation: Frank O. Ozoh. (2020). PATHWAY TO REOPENING ECONOMIC ACTIVITIES IN THE ECOWAS REGION AMIDST COVID19 PANDEMIC. International Journal of Research -GRANTHAALAYAH, 8(6), 30-35. https://doi.org/10.29121/granthaa layah.v8.i6.2020.363

Received Date: 02 May 2020

Accepted Date: 21 June 2020

Keywords:

Protocol-Compliance Activities

Covid-19 Infection Contour

Covid-19 Pandemic

$\mathrm{N}$-Curve Hypothesis

Social Distancing

S ECOWAS

\section{ABSTRACT}

The Covid-19 Pandemic has adversely impacted the world economy, including those of Economic Community of West African States (ECOWAS). The border closures, lockdowns and social distancing have, to a varying degree, affected economic activities negatively. These include, among others, the loss of lives, jobs, outputs and national incomes. But how and when to begin to maintain some levels of economic activities amidst increasing infection rate, death rate, and hospitalization rate is a major issue of disagreement between health experts, political leaders and economists.

In this article, therefore, we shall attempt to illustrate a pathway towards the reopening of economic activities in a corona virus economy or community, following a graphic explanation of the virus infection rate over a period of time which resembles the English small letter ' $n$ '.

\section{INTRODUCTION}

The Coronavirus Pandemic has adversely affected the movement of people, goods and services across borders within the Economic Community of West African States (ECOWAS) region and beyond. This is particularly problematic due to the border closures and lockdowns which have impeded the flow of commerce (trade and its aids), including the movement of people across the national boundaries.

We know that through trade intercourse and aids to it, the national incomes, outputs and jobs of the trading partners within the region hang together.

For this reason, therefore, any adverse milieu like the Covid-19 Pandemic, with the increasing rate of transmission and infection within ECOWAS member countries and across borders, will adversely impact on national incomes, outputs and jobs among trading partners in the region.

Since the mode of infection and transmission is by means of physical contact among human beings, and the volume of transactions are effected through accompanied arrangements by traders, how do we maintain, if not to increase, the volume and value of trade (goods and services) and the physical movement of traders as to stabilize

(C) 2020 The Author(s). This is an open access article distributed under the terms of the Creative Commons Attribution License, which permits unrestricted use, distribution, and reproduction in any medium, provided the original author and source are credited. 
Pathway to Reopening Economic Activities in The Ecowas Region Amidst Covid-19 Pandemic

the growth rate of incomes, production and employment among trading partners in this era of the pandemic within the region?

This question has remained the arcanum among traders, political leadership and health experts within the region.

In this regard, it is suggested that the optimal option is to have an effective vaccine for Covid-19 prevention of infections.

However, in the absence of a preventative vaccine, then the application of absolute lockdown and closure of national borders, which will diminish trade intercourse, people's movement within and across borders, and eventually impact negatively on individuals and aggregate national incomes, outputs and jobs within the community is clearly discernible.

Again, we have the option of minimising infection rate and transmission by applying and utilising Covid-19 infection prevention protocols. For example, the constant decontamination with disinfectant of equipment and vehicles for the movement of people and goods across national boundaries, the application and utilisation of PPE (Personal Protective Equipment), including face masks and hand sanitizers and/or regularly washing of hands with soap under running water. Also, the protocol will include regularly testing, tracing, tracking and isolating travellers with Covid-19 infections for symptomatic display of temperature and other indications.

Unfortunately, the lag between the administration of tests and results availability will definitely bring about some elements of chaos due to large number of goods, traders and migrants at the borders.

Then, the problem will be how to determine and deal with the level of chaos that is tolerable for a given quantum of movement of goods, services and travellers across ECOWAS borders. Also, what levels of movement of goods, services and people with the observance of the Covid-19 prevention of transmission protocols will be within the managerial capacity of the border controllers?

In this regard and in the absence of clarity and certainty, for the pathway to reopening of economic activities we shall adopt the n-curve hypothesis to explain with some certainty the infection rate of the Covid virus and the possibilities of reopening economic activities. This is done so that as the rate of infections declines progressively with acceleration or deceleration, then the reopening of economic activities across national frontiers is effected quickly or less quickly with caution, respectively.

\section{ECOWAS, MEMBERSHIP, COVID-19 AND ECONOMIC INTEGRATION}

The Economic Community of West African States (ECOWAS) is a regional economic and political union of West African States, comprising of 15 member countries. These countries together occupy a geographical area of about $5,114,162$ square $\mathrm{km}$. It has an estimated population of more than 349 million people.

ECOWAS was founded in May 28, 1975 in Lagos, Nigeria with a subsidiary of West African Economic and Monetary Union at present. The main goal of ECOWAS is to promote economic integration among member countries through cooperation.

The founding members of the union include Benin, Burkina Faso (formerly known as Upper Volta), Cote d' Ivoire, Gambia, Ghana, Guinea, Guinea-Bissau, Liberia, Mali, Mauritanian (which left in 2002), Niger, Nigeria, Senegal, Sierra Leone and Togo.

The major goals of ECOWAS, among others, include fostering economic cooperation among members and raising the living standards of her citizens by enhancing and maintaining economic growth with stability in the region.

In May 19, 2020, ECOWAS flagged off its Covid-19 Pandemic programme along with the distribution of hygiene materials to the displaced population in Nigeria. Also, on April 23, 2020, ECOWAS held a videoconference summit on developments and impacts relating to the Covid-19 Pandemic.

As at April 22, 2020, the ECOWAS region recorded more than 6,000 cases of Corona virus infections with a death toll of about 158.

However, before the end of May, 2020, Nigeria alone recorded more than 5,959 infection cases, notwithstanding the per capita implications in terms of population size. This is an indication that the Covid-19 Pandemic is rising exponentially within the region. Given this Covid-19 milieu in the Union, ECOWAS appointed Buhari as the Coronavirus pandemic response 'champion' during the video conference summit.

In 2015, ECOWAS total estimated GDP in nominal terms stood at USD 675 billion with per capita record of USD 1,985. With the arrival of the Covid-19 pandemic, this economic record is at stake. 
The ECOWAS pre-Covid-19 economic growth rate forecast was initially put at 3.3 per cent. However, with the expectation that the Coronavirus pandemic will come to an end by June 2020, it has been revised downward. For this reason, ECOWAS response plan against the pandemic was to take into account the fight against the spread of the virus, coupled with a post- Covid-19 pandemic economic recovery plan.

Furthermore, ECOWAS agreed to a coordinated increase in testing with more capacity building in order to limit the impact of the pandemic within the region.

To this end, the union member states are committed to allocating a minimum of 15 per cent of their annual budget to strengthen health care services within the region. However, it must be noted that this promise was also made in 2014 for the first time in Accra, Ghana with little or no compliance, indicating the lack of political will among ECOWAS members and their political leaders.

This has accounted for the lack of the required health care infrastructure to enable the region meet the basic requisites towards fighting the Covid-19 pandemic in the region.

\section{THE n-CURVE HYPOTHESIS and COVID-19 INFECTION RATE}

Regarding the loss of lives, jobs and boons of economic activities, we follow the path of the $\mathrm{n}$-Curve hypothesis (see Ozoh, 2020).

The loss of lives due to Covid-19 pandemic cannot be recovered in the future but the loss of jobs, economic depression and recession, no matter the magnitude will pass away as part of the cyclical trends in a nation's economic history.

As the Covid-19 infection rates are still rising in different countries, coupled with the rising rates of hospitalizations, intubations and deaths, then the productive, the distributive and the absorption capacities of the economy will be adversely affected.

Since a healthy nation is a productive nation, it follows, therefore, that in order to reopen the economy in phases, we follow the $\mathrm{n}$-Curve hypothesis that records the infection rate on the Y-axis and time period in weeks on the Xaxis of any graphical illustration in economic theory. The rate at which the Covid-19 infection grows, resembles that of the English letter small ' $n$ '. Please note that the shape of the letter ' $n$ ' may not follow any unique pattern. This is because not all the typewriter machines give a particular shape of ' $n$ '. Therefore, all that we require for our analysis is that the Covid-19 infection contour, resembles the shape of the letter small ' $n$ ' in the English alphabet.

Observe the symmetry of the $\mathrm{n}$-Curve, indicating that $\mathrm{OA}$ is symmetrical to $\mathrm{CD}$, and that $\mathrm{AB}$ is symmetrical to $\mathrm{BC}$. Also, $\mathrm{aB}$ is symmetrical to $\mathrm{Bb}$. Although not drawn in the diagram, the apex phase of the curve may produce a wCurve effect over a period of time, but so long as the up-turnings are not more protracted than the down-turnings, as to overwhelm the decreasing slopes, then the net infection rate would remain either fairly constant and/ or decline eventually.

As we have seen from Figure A, the rising phase of the Covid-19 infections contour will show an increase with deceleration, then may pick-up with acceleration. However, if the authorities have a hold on the spread of the infection and transmission, then the rise in the Covid-19 infections contour will be flatter, longer or shorter in time period, depending on the effectiveness of the measures in the reporting Corona virus economy.

The third phase is that part in which the curve has attained its apex height and has not started falling. At this point, the curve is at its apex and may even depict a fairly constant range at the apex region.

The fourth path is the declining phase in which the infection rate has ceased to increase but is either declining with acceleration (steeper and shorter in time period) or with deceleration (flatter and longer in time period).

The fifth phase is the phase in which the infection rate has ceased and the curve is decreasing with deceleration till at a time the infection rate peters out at point $\mathrm{D}$. At this point, $\mathrm{n}$-Curve infection rate is zero, touching the $\mathrm{X}$-axis to produce a post pandemic result. However, if the infection rates remain very low and negligible, then the $n$-Curve may not touch the X-axis. 
Figure A

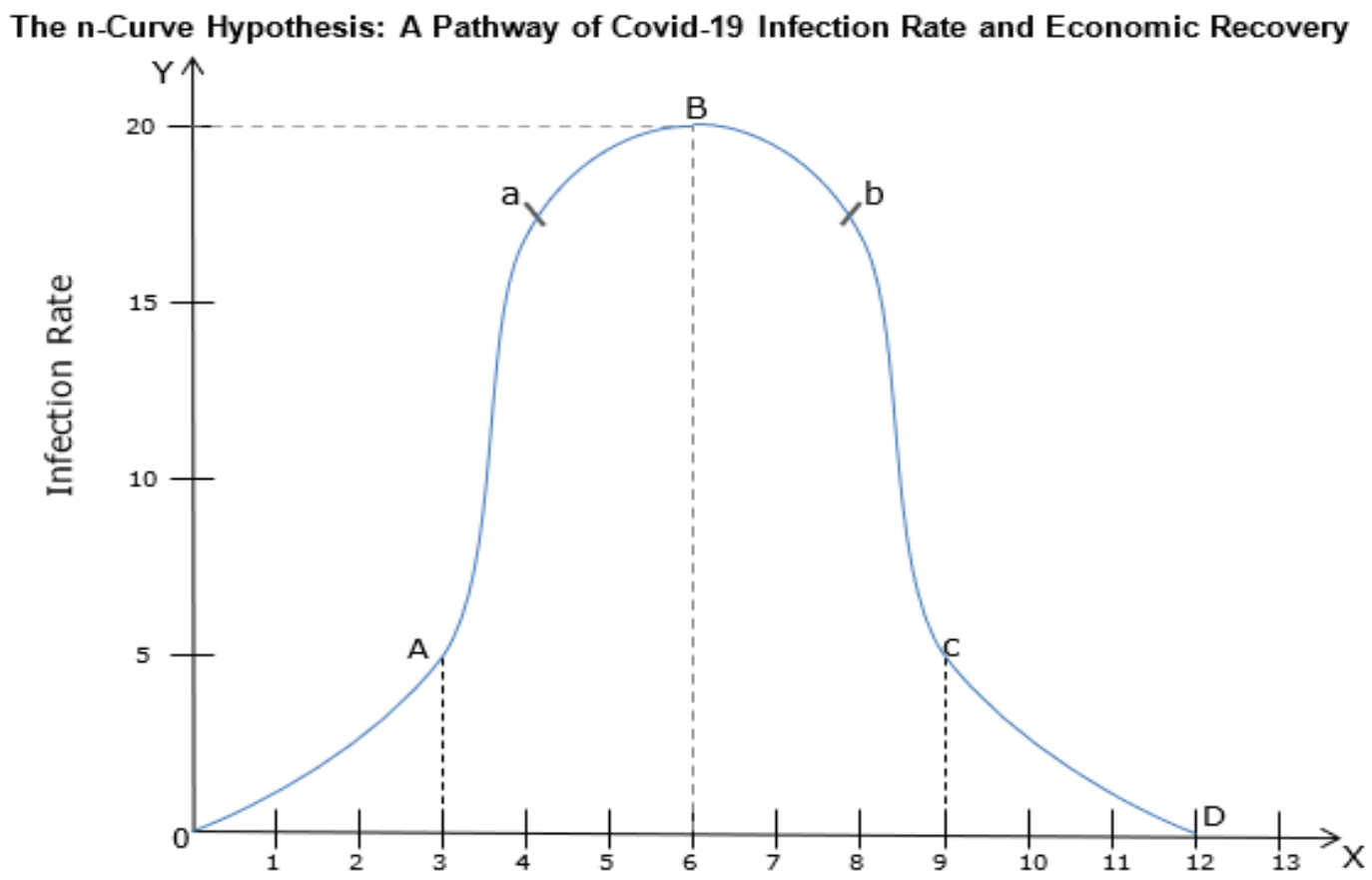

Time Period in Weeks

Figure A measures the Time Period of Infection in weeks along the $x$-axis, while the $y$-axis measures the infection, death or hospitalization rates in percentages. The n-Curve has four distinguishing parts and they are: Part OA, Part AB, Part BC and Part CD. Beginning from the point of origin (0), the n-Curve infection rate of Covid-19 increases with deceleration till point $A$, that is $O A$ range. Then, the infection rate increases with acceleration within the $\mathrm{AB}$ range particularly in the $\mathrm{Aa}(17.5 \%)$ range, that is, the range covering between $5 \%$ and $20 \%$ infection, death or hospitalization rate. Point $B$ is the apex at which the infection rate is maximum at $20 \%$ rate of infection. Observe that between $\mathrm{aB}$ and $\mathrm{Bb}$, the infection rate could be fairly constant, that is, within the ab range. Then, after point $\mathrm{B}$,

that is, within the range $\mathrm{BC}$ particularly in the $\mathrm{Bb}$ range, then the infection rate decreases with acceleration and within CD range declines with deceleration.

\section{N-CURVE AND THE REOPENING of ECONOMIC ACTIVITIES}

Then, beginning with the Apex Phase, which could be a point or exist in a relatively constant infection rate, which is also an indication that the authorities are having a hold on the rate of infections, but that the downward journey of the Covid-19 infections contour has not started in earnest.

In this phase, therefore, all the essential productive and distributive channels of economic activities, including non-essential but relatively Covid-19 protocol-compliant activities could be allowed to reopen.

Then, with regards to the declining phase of the Covid-19 infection rates, it will depend on whether or not the infection rate is declining with deceleration or with acceleration, in other words, whether or not the falling tendency rates are flatter or steeper, respectively.

Furthermore, it is noteworthy that in the falling phases of Covid-19 infections curve, a steeper fall is preferable than a flatter fall, unlike in the rising phase. In the rising phase, a flatter rate is preferable than a steeper rate, notwithstanding the temporal dimensions and/or time element factors. However, the shorter and flatter is the duration of the rise in the Coronavirus infection rate curve, then the economic lockdown in a given economy is relatively pointless. Also in this regard, a steeply rising phase of the curve comes with some elements of panic, fear and disruption. For this reason, this type of rise in the Covid-19 contour is preferentially sub optimal for the authorities. 


\section{SUMMARY}

From the foregoing, we observe that the Coronavirus Pandemic has adversely impacted the ECOWAS member countries and the economy of the region due to border closures and lockdowns, inhibiting the movement of people and goods across national boundaries within ECOWAS REGION and beyond. As the Covid-19 rate of infection and death toll increases, the challenges of inadequacy of infrastructural facilities, particularly those of the health sector, weakens the region's capacity to fight the Pandemic.

For this reason therefore ECOWAS member states heavily relied on lockdowns, border closures, social distancing, self-isolation and other Covid-19 prevention protocols. Furthermore, the capacity to fight the virus was debilitated by massive poverty and corruption within the region. Again, because the masses live from "hand-tomouth", their capacity to withstand hunger in an extended duration of lockdowns and border closures is very weak.

As the poor masses put pressure on the authorities to reopen economic activities, particularly in the absence of social-security/unemployment benefits in the region, amid rising rate of infections, disagreements between political leaders, economists and medical experts are ensured. It is for this reason the $\mathrm{n}$-Curve Hypothesis is presented as a pathway towards economic recovery albeit in phases amidst various rates of the Covid-19 infections.

Also, it is important to note that the rate of infections declines faster within a short period of time in a steeper contour, than in a flatter fall which spreads over a longer period of time, requiring the economic activities to gradually reopen in phases, depending on the enabling environment.

Therefore, the loss of jobs, outputs and income, including galloping inflation rate that were induced by Covid19 Pandemic could peter out, but the quantum of deaths or death toll (loss of love ones) will linger and could impact negatively on the economy due to the loss of the industrial army of labour in a given state of art.

For this reason, what will be the quantum of deaths acceptable for a given level of economic freedom certainly have remained the arcana for the political, economic and health leaders in these variety of economies during this era of the Coronavirus pandemic.

That we must do something, and that too very fast, is not in doubt, but to put the lives of the community as secondary to economic activities by reopening the economy at the rising phase of the Covid-19 infection rates, particularly when it is increasing with acceleration, is certainly placing the cart before the horse.

\section{RECOMMENDATION}

From the foregoing, we recommend as follows:

- That within the rising phase of the Coronavirus infections rate or death toll only the essential lines of commodities' production and distribution should be allowed across borders and lockdowns. This will include the movement of medical experts, equipment, facilities and drugs.

- That between the apex and the declining phases of the Covid-19 infections contour, reopening of the border closures, lockdowns and economic activities within the ECOWAS region and member countries should be in phases. So that as the infection rate declines further, more economic activities are reopened with caution, ensuring that the infection rates do not rebound within this range till the minimal or zero infection rate is attainable.

- That if total lockdown and border closures are to be applied in the absence of a workable social security/unemployment benefits facility from the authorities, then it is worthwhile for the member countries to employ food and medical items distribution as palliatives to mitigate hunger and illnesses during the period of the lockdown and restrictive movement.

\section{CONCLUSION}

In conclusion, it is our belief that if the n-Curve pathway is followed by ECOWAS and member countries in fighting the infection rates and reopening of the economic activities within the region, then the adverse impact of Covid-19 pandemic will be minimal on the masses and the economy. 


\section{SOURCES OF FUNDING}

None.

\section{CONFLICT OF INTEREST}

None.

\section{ACKNOWLEDGMENT}

None.

\section{REFERENCES}

[1] Anyanwu, Aham, Ed., (1995): "Enabling Environment for Economic Growth,” Barloz Publishers Inc., Benin, Nigeria.

[2] Bamfo, Napolean (2013): “The Political and Security Challenges Facing 'ECOWAS' in the Twenty-First Century: Testing the Limits of an Organization's Reputation" International Journal of Humanities and Social Science, vol.3, no.3 (February 2013).

[3] Chigbuh, E.E. and Chigbuh, A.E. (1995): “Creating the Enabling Health Environment for Accelerated Economic Growth in Nigeria: Problems and Possibilities," in Enabling Environment for Economic Growth, Barloz Publishers Inc., Benin, Nigeria.

[4] Corona Virus: ECOWAS Appoints Buhari as Pandemic Response 'Champion.' www.theafricareport.com (April 27, 2020).

[5] ECOWAS: A Compendium of Protocols, Conventions and Decisions relating to the Free Movement of Persons and Goods. Economic Community of West African States (ECOWAS), a Publication of the Executive Secretariat of ECOWAS.

[6] ECOWAS (2020): “Covid-19: ECOWAS Flags off Distribution of Hygiene Materials to Displaced Populations in Nigeria," http://ecowas.int>covid-19-e (May, 20).

[7] ECOWAS/ USAID (2018): Regional Partner in Economic Growth: ECOWAS/ USAID, http://www.usaid.gov (September).

[8] Onwumere, J.U.J. and Ozoh, F.O. (Eds) (2010): “Economic Development and Management," Quarterly Press Ltd, 59 Moorehouse Street, Ogui, Enugu, Nigeria. : "Planning for Economic Development: with Illustrations from Nigeria," Quarterly Press Ltd, 59 Moorehouse Street, Ogui, Enugu, Nigeria.

[10] Ozoh, F.O. and Aja-Nwachukwu, I. (Eds) (2012): "Cost and Output Management in a Growing Manufacturing Firm," in Aspects of Business Management for Manufacturing Firms, ZNC-Amabilis Ltd., 4a Njoku/ 11 Okigwe Road, Aba, Abia State Nigeria.

[11] Regional Partner in Economic Growth: ECOWAS USAID, http://www.usaid.gov (September 28, 2018).

[12] Saving, T.R. (1961): "Estimation of Optional Size of Plant by the Survivor Technique," Quarterly Journal of Economics.

[13] Shepherd, W.C. (1967): “What Does the Survivor Technique show about Economies of Scale?" Southern Economic Journal. 